\title{
IN SITU EXAMINATION OF MOVING CRACK TIPS IN ORDERED INTERMETALLICS*
}

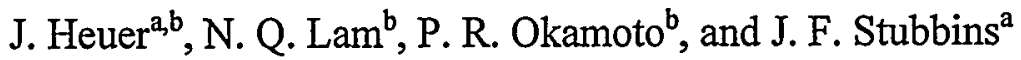 \\ ${ }^{a}$ Department of Nuclear Engineering \\ University of Illinois \\ Urbana, IL 61801 \\ ${ }^{\mathrm{b}}$ Argonne National Laboratory \\ Materials Science Division \\ Argonne, IL 60439
}

January 1999

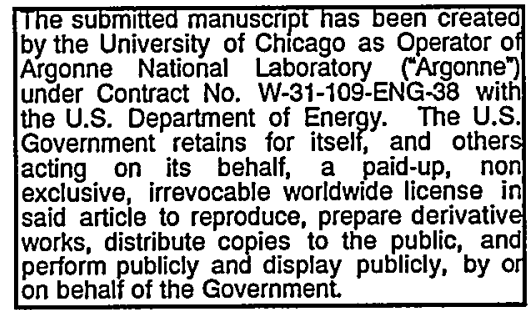

REOEN

OCT 131999

OSTI

Manuscript to be submitted to the Materials Research Society, November 30 - December 4, 1998, in Boston, MA.

\footnotetext{
*Work supported by the U.S. Department of Energy, Basic Energy Sciences-Materials Sciences, under contract No. W-31-109-Eng-38.
} 


\section{DISCLAIMER}

This report was prepared as an account of work sponsored by an agency of the United States Government. Neither the United States Government nor any agency thereof, nor any of their employees, make any warranty, express or implied, or assumes any legal liability or responsibility for the accuracy, completeness, or usefulness of any information, apparatus, product, or process disclosed, or represents that its use would not infringe privately owned rights. Reference herein to any specific commercial product, process, or service by trade name, trademark, manufacturer, or otherwise does not necessarily constitute or imply its endorsement, recommendation, or favoring by the United States Government or any agency thereof. The views and opinions of authors expressed herein do not necessarily state or reflect those of the United States Government or any agency thereof. 


\section{DISCLAIMER}

Portions of this document may be illegible in electronic image products. Images are produced from the best available original document. 


\section{IN SITU EXAMINATION OF MOVING CRACK TIPS IN ORDERED INTERMETALLICS}

J.K. Heuer (a,b), N.Q. Lam (b), P.R. Okamoto (b), J.F. Stubbins (a)

(a) Department of Nuclear Engineering, University of Illinois, Urbana, IL 61801

(b) Materials Science Division, Argonne National Laboratory, Argonne, IL 60439

\section{ABSTRACT}

Recent studies have shown that high stress concentrations at moving crack tips in the intermetallic compound NiTi can induce a crystalline-to-amorphous (C-A) transformation of the crack tip region. This stress-induced C-A transformation has a temperature dependence and crystallization behavior similar to those of ion irradiation-induced C-A transformation of NiTi. The present study examines if these similarities between stress- and irradiation-induced amorphization hold true for two other intermetallic compounds, $\mathrm{CuTi}$ and $\mathrm{Ni}_{3} \mathrm{Ti}$. In situ straining was performed in an intermediate-voltage transmission electron microscope. The presence or absence of an amorphous phase was determined by dark field imaging and selected area diffraction of crack tip regions. Crack tips in both $\mathrm{CuTi}$ and $\mathrm{Ni}_{3} \mathrm{Ti}$ were found to remain crystalline upon fracture. The observed absence of stress-induced amorphization in $\mathrm{Ni}_{3} \mathrm{Ti}$ is consistent with its known absence during irradiation, but the absence in CuTi differs from its known irradiation-induced amorphization behavior. Reasons for the similarity and difference are discussed.

\section{INTRODUCTION}

A fundamental understanding of fracture is of considerable technological importance. While it is known that the stress concentration at a crack tip is the primary driving force for fracture, the mechanism of strain energy release is not well understood. In this study, we investigate the possibility whether this release can occur via local melting of the crack tip.

This possibility is illustrated in Figure 1 which shows the free energy curves of an unstressed perfect crystal, two stressed crystals, and the liquid. Also shown are the ideal glass [1], the glass that has the same entropy as a perfect crystal, and two unrelaxed glasses associated with cooling rates such that $T_{g 1}>T_{g 2} ; T_{g i}$ represents the respective glass transition temperatures, and $T_{K}$ is the ideal glass transition temperature as defined by Kauzmann [1]. Figure 1 illustrates how heat-induced (ordinary) melting of a perfect crystal occurs when its free energy drops to a level equal to that of the liquid; the temperature at this point $\left(\mathrm{T}_{\mathrm{m}}^{\mathrm{o}}\right)$ is defined as the melting temperature. However, the free energy curve for the stressed crystal intersects that of the liquid at a temperature $\mathrm{T}_{\mathrm{m}}^{\sigma}$ below that for melting of the unstressed crystal. This stress-induced reduction in the melting temperature can also occur locally at regions of high stress concentrations such as at crack tips.

Further evidence supporting the possibility of stress-induced melting of the crack tip comes from Monte Carlo (MC) simulations of fracture [2]. In these simulations, fcc elemental crystals, subjected to uniaxial tension, were observed to melt prior to failure at temperatures as low as $0.35 \mathrm{~T}_{\mathrm{m}}^{\mathrm{o}}$. These MC simulations also indicate that the melted regions (which cannot sustain a tensile load) immediately recrystallize leaving behind no trace that melting has occurred. This nearly instantaneous recrystallization indicates that the detection of stress-induced melting may not be possible for elemental crystals. However for intermetallic compounds, stressinduced melting may be detectable at low temperatures as a stress-induced crystal-to-amorphous 
(C-A) transformation. This is illustrated in Figure 1 which shows that the C-A transformation can be induced by raising the free energy of a crystal to the level of the ideal glass (which is the glassy state with the lowest free energy). For example, C-A transformations in intermetallics such as NiTi can be readily induced by particle irradiation. However, direct observation of a stress-induced C-A transformation at crack tips has been reported only recently [3]. In situ TEM studies of fracture in NiTi (Figure 2a) have revealed that this stress-induced $\mathrm{C}-\mathrm{A}$ transformation has a similar temperature dependence as ion irradiation-induced $\mathrm{C}-\mathrm{A}$ transformation of NiTi. In addition, the isothermal crystallization temperature of the resulting glass was found to be identical to that predicted for the ideal glass, providing strong support for the stress-induced melting concept.

In this paper, we report the results of our recent examinations of crack tips for signs of stress-induced amorphization in two other compounds: $\mathrm{CuTi}$, which undergoes an electron irradiation-induced $\mathrm{C}-\mathrm{A}$ transformation, and $\mathrm{Ni}_{3} \mathrm{Ti}$, which does not $[4,5]$. Cracks in these compounds propagate during straining inside an intermediate-voltage $(300 \mathrm{kV})$ electron microscope and are observed in situ using dark-field imaging and selected area diffraction.

\section{EXPERIMENT}

Miniature tensile TEM specimens were prepared from alloy buttons by diamond sectioning and subsequent polishing to a $200 \mu \mathrm{m}$ thickness. Disks $3.0 \mathrm{~mm}$ in diameter were cut from the thinned material with a core drill, and two parallel ends were truncated with a wire saw to produce modified disk specimens $2.5 \mathrm{~mm}$ wide necessary to fit on stainless steel straining bases. Modified disks were then annealed at $900^{\circ} \mathrm{C}$ for 1 hour to remove any mechanical damage before electropolishing to electron transparency. Prior to straining ( 24 hours), the disks were attached to the straining bases using a vacuum epoxy.

In situ straining was performed in a Hitachi 9000 TEM using a single tilt heating-straining stage. Crack tips and edges that propagated during straining at room temperature were examined. The presence or absence of amorphization was determined by selected area diffraction (SAD) from these regions using a 10 micron selected area aperture. Cracks in both electron-transparent and electron-opaque regions were examined since the previous NiTi studies indicated amorphous halos were easier to detect in thicker regions due to the greater sampled diffracting volume.

\section{RESULTS}

The result of fracture in CuTi is discussed first. CuTi specimens had large-grain microstructures so that crack propagation occurred mainly through single crystalline regions rather than along grain boundaries. Upon application of tensile stress, crack propagation occurred very quickly. In fact, propagation could not be captured by the 30 frame/second recording speed of the video cassette recorder used to monitor the in situ experiments. Dislocation bands were observed to form ahead of crack tips during propagation. Examination of crack tips and edges for signs of amorphization was done by analyzing SAD patterns from 35 different regions in $\mathrm{CuTi}$. In all of these patterns, no diffuse intensity halos typical of an amorphous structure were detected. Instead, crack tips and edges either remained crystalline or became polycrystalline. Figure $2 \mathrm{~b}$ shows a typical crack that propagated in $\mathrm{CuTi}$ along with its associated polycrystalline diffraction pattern. The strong complete ring comes from CuTi (110) reflections; the other weaker rings can be indexed to additional CuTi reflections. Such polycrystalline rings were detectable only in thick regions of the specimen where the diffracting volume was sufficient to produce ring patterns. 
Like $\mathrm{CuTi}$, the $\mathrm{Ni}_{3} \mathrm{Ti}$ specimens had a large-grain microstructure, and subsequent crack propagation was through single crystalline regions. As in the case of $\mathrm{CuTi}$, dislocation bands were detected extending far ahead of crack tips after propagation. Examination for amorphization was performed by analyzing SAD patterns from 32 crack tips and edges, and like CuTi, no diffuse intensity halos were detected which revealed that crack tip regions remained single crystalline or became polycrystalline. However, in this case, the majority of crack tips and edges were not polycrystalline. Figure $2 \mathrm{c}$ shows a typical crack that propagated in $\mathrm{Ni}_{3} \mathrm{Ti}$. Its associated $\mathrm{SAD}$ pattern has the same single crystalline structure as the matrix away from the crack regions. Polycrystalline rings were detected in only 2 of the 32 regions examined.

These results indicate that neither $\mathrm{CuTi}$ nor $\mathrm{Ni}_{3} \mathrm{Ti}$ undergo a stress-induced $\mathrm{C}-\mathrm{A}$ transformation. The absence of this transformation in $\mathrm{Ni}_{3} \mathrm{Ti}$ was expected since it does not become amorphous during particle irradiation. However, the absence of a stress-induced C-A transformation in CuTi was surprising since it is highly susceptible to electron-induced amorphization. The unexpected behavior of $\mathrm{CuTi}$ can be examined in terms of the driving force for the C-A transformation. In order for such a transformation to occur, the free energy of the perfect crystal must be raised to the level of the ideal glass. In the case of particle irradiation, antisite defects (chemical disorder) are known to provide the primary driving force for amorphization of $\mathrm{CuTi}$. The process of chemically disordering a crystal lattice allows strain energy (and hence free energy) to accumulate to the point where a C-A transformation is possible. However, the driving force mechanisms for stress-induced amorphization are still unclear. For NiTi, the evidence suggests the involvement of chemical disorder. The majority (20 of 25) of SAD patterns from partially amorphized crack tips that propagated below $300^{\circ} \mathrm{C}$ in $\mathrm{NiTi}$ showed no superlattice reflections indicating the absence of chemical long-range order. However, NiTi superlattice reflections were present in the majority (15 of 22) of SAD patterns taken from cracks that propagated above $300^{\circ} \mathrm{C}$ where thermal recovery was possible.

In contrast to the behavior of $\mathrm{NiTi}$, the majority (7 of 10) of SAD patterns from crack tips and edges in CuTi revealed that superlattice reflections were present. This absence of chemical disorder provides an explanation why CuTi is not amorphized by stress at crack tips while it is amorphized by particle irradiation. These results suggest that chemical disorder is an important driving force for stress-induced amorphization and that either the excess free energy associated with chemical disordering at crack tips in $\mathrm{CuTi}$ has not reached the point necessary to drive the C-A transformation or that the strain energy must have been released by another mechanism during fracture. The nature of this alternate process is unclear, but the observation of dislocation bands ahead of crack tips suggests that some strain energy is dissipated by dislocation emission. Figure 3 shows a band of dislocation segments and loops extending horizontally from a typical crack tip. They are superimposed on long dislocations (at a $45^{\circ}$ inclination) that were present before fracture. Analysis of the dislocations indicates that they move along (001) slip planes. This identification is based on both TEM analysis and atomistic simulations. TEM analysis indicates that the dislocations appear edge-on when the (001) planes are tilted perpendicular to the viewing direction; in addition, atomistic simulations [6] indicate that vacancy migration energies are very low along these planes. The fact that dislocations move along these slip planes so far ahead of cracks indicates that strain energy from the tips can be dissipated over this entire distance.

\section{CONCLUSIONS}

Crack tips were examined in both $\mathrm{CuTi}$ and $\mathrm{Ni}_{3} \mathrm{Ti}$ for signs of a stress-induced $\mathrm{C}-\mathrm{A}$ transformation. Such a transformation was not detected in either material. This is consistent 
- with the irradiation behavior of $\mathrm{Ni}_{3} \mathrm{Ti}$, but the absence of stress-induced amorphization in $\mathrm{CuTi}$ differs from its known irradiation-induced amorphization behavior. This difference in behavior of $\mathrm{CuTi}$ is attributed to the absence of chemical disorder at crack tips necessary to drive a C-A transformation whereas in the case of particle irradiation, chemical disorder provides most of the driving force for amorphization. Also in $\mathrm{CuTi}$, the long bands of dislocations extending from crack tips suggest that dislocation emission is an important energy release mechanism.

\section{ACKNOWLEDGMENTS}

This work was supported by the U.S. Department of Energy, Basic Énergy SciencesMaterials Sciences, under contract W-31-109-Eng-38. Special thanks are extended to B. Kestel for aid with specimen preparation and E. Ryan and S. Ockers of the Argonne HVEM-Tandem Accelerator Facility for assistance with in situ straining experiments.

\section{REFERENCES}

1. W. Kauzmann, Chem. Rev. 43 (1948) 219.

2. R.M. Lynden-Bell, J. Phys.: Condens. Matter 7 (1995) 4603.

3. P.R. Okamoto, J.K. Heuer, N.Q. Lam, S. Ohnuki, Y. Matsukawa, K. Tozawa, and J.F. Stubbins, Appl. Phys. Lett. 73 (1998) 473.

4. P.R. Okamoto and M. Meshii, "Solid-State Amorphization-Particle Irradiation," Science of Advanced Materials, edited by H. Weidersich and M. Meshii (1988) 33.

5. J. Delage, O. Popoola, J.P. Villain, and P. Moine, Mater. Sci. and Engin. A115 (1989) 133.

6. J.R. Shoemaker, R.T. Lutton, D. Wesley, W.R. Wharton, M.L. Oehrli, M.S. Herte, M.J. Sabochick, and N.Q. Lam, J. Mater. Res. 6 (1991) 473. 


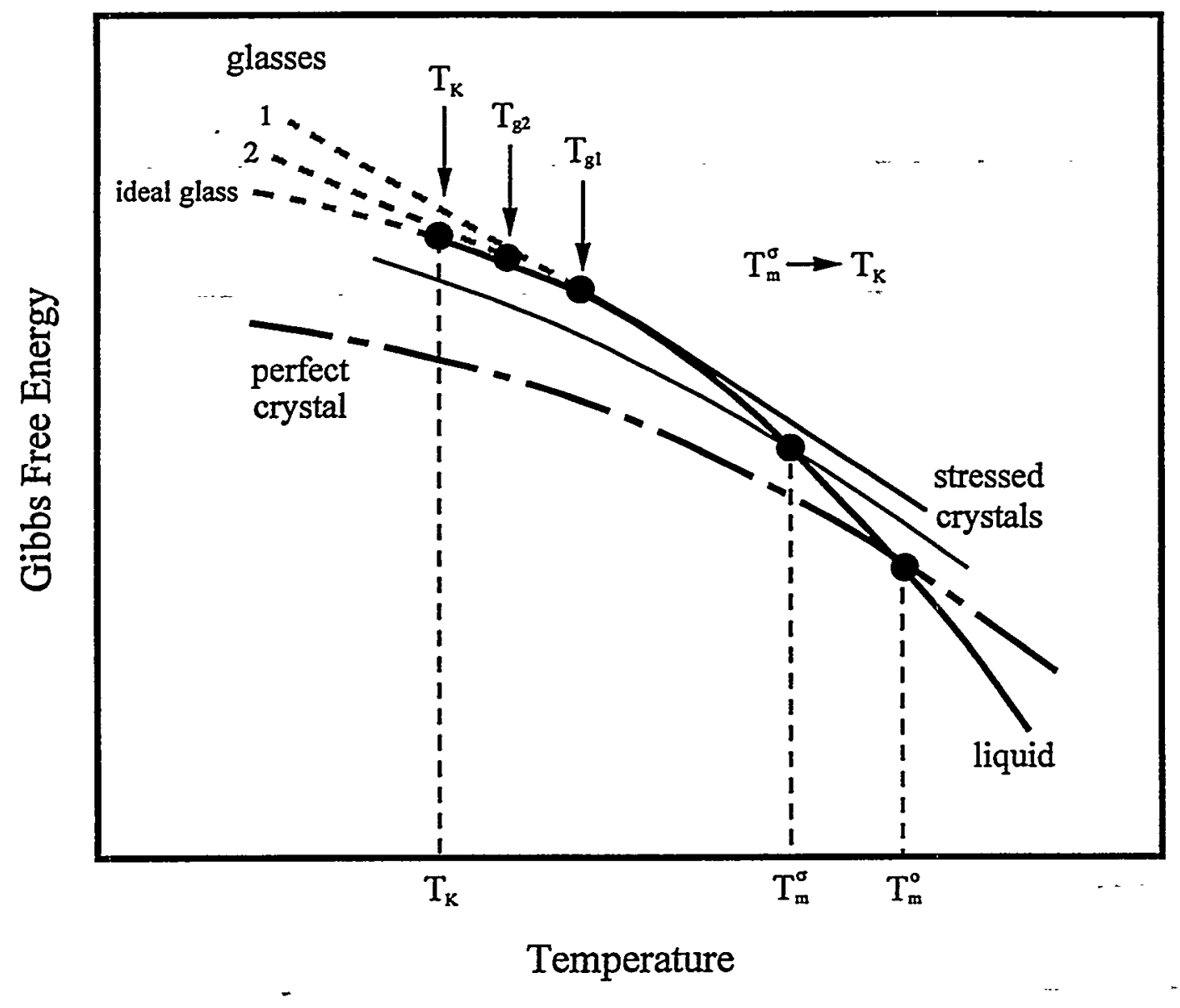

Figure 1. Thermodynamic basis for stress-induced melting criterion. 

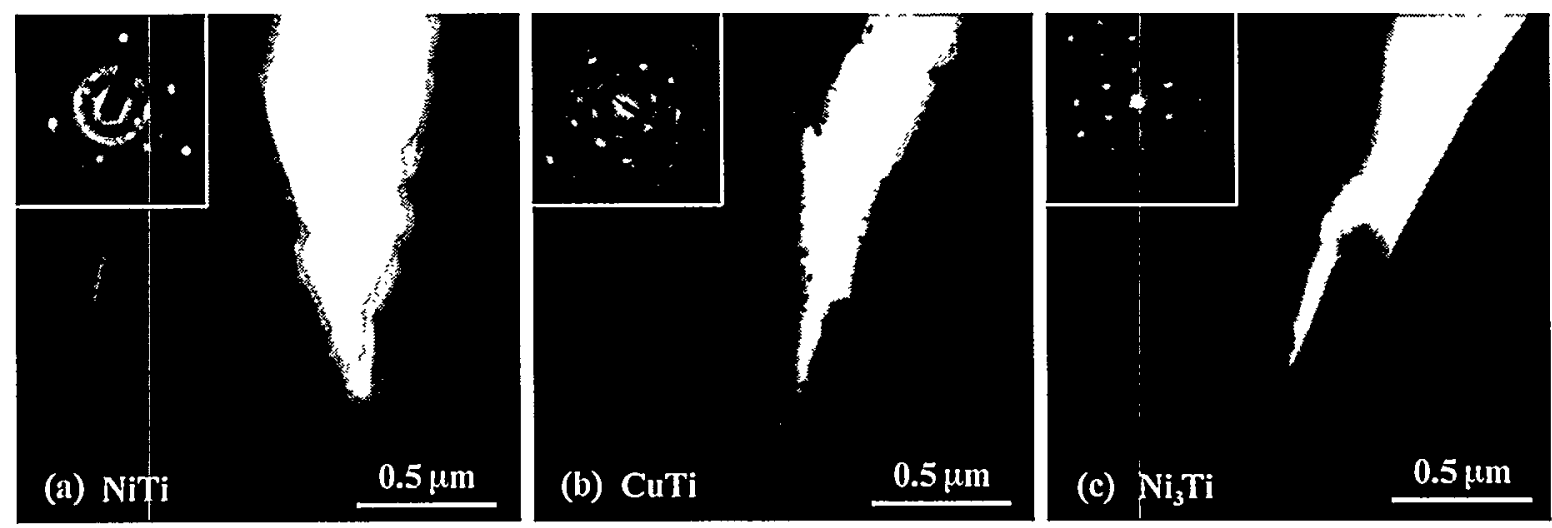

Figure 2. Typical cracks that propagated in (a) $\mathrm{NiTi}$, (b) $\mathrm{CuTi}$, and (c) $\mathrm{Ni}_{3} \mathrm{Ti}$ at ambient temperature and the selected area diffraction (SAD) patterns from their tips.
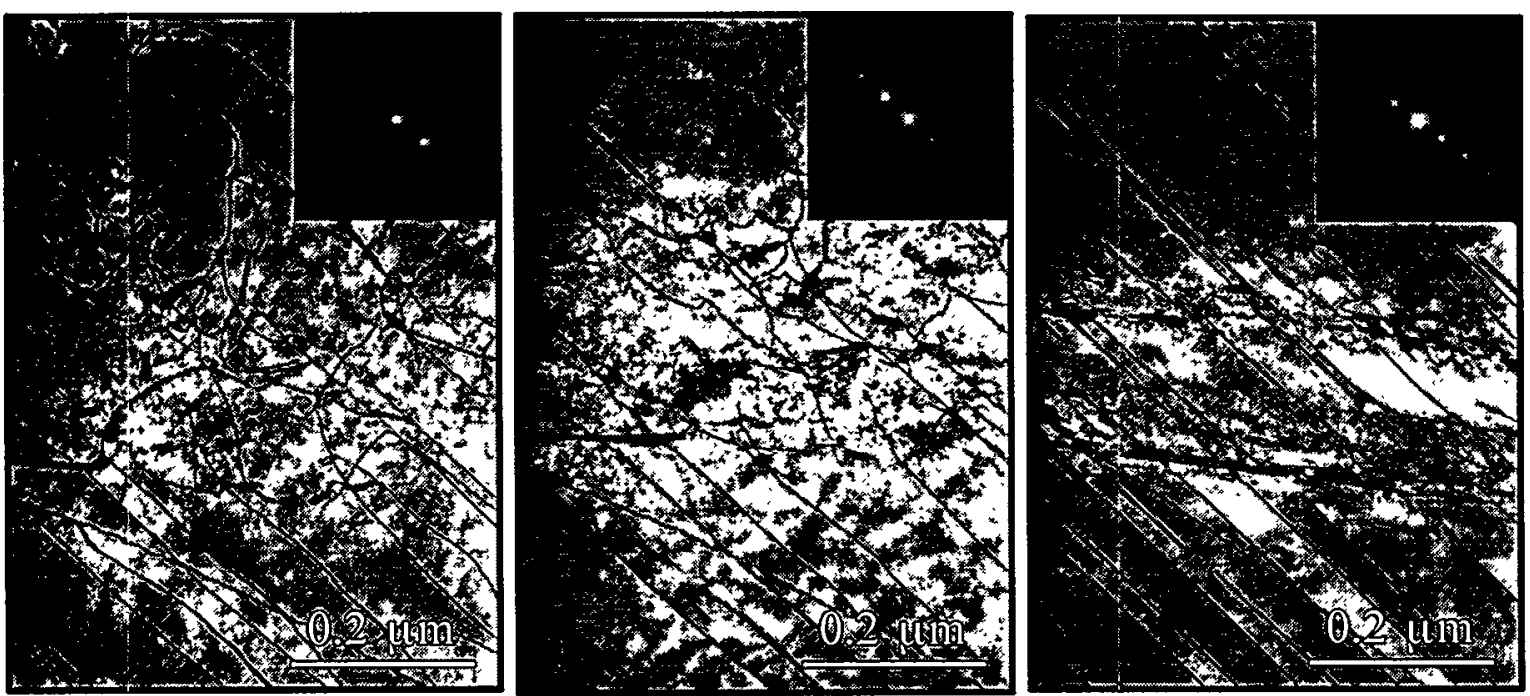

Figure 3. Dislocation band observed ahead of typical crack tip. Imaging conditions are such that the (001) planes are inclined at (a) $61^{\circ}$, (b) $79^{\circ}$, and (c) $90^{\circ}$ to observation direction. 